Condensed Matter Physics, 2004, Vol. 7, No. 2(38), pp. 275-284

\title{
The electroconductivity of the liquid alloys of transition metals
}

\author{
V.T.Shvets, S.V.Savenko, S.V.Datsko \\ Odesa State Academy of Refrigeration, \\ 1/3 Dvorianska Str., 65026, Odesa, Ukraine
}

Received April 22, 2004

\begin{abstract}
The concentration dependance of electroresistivity of the liquid binary alloys of transition metals $\mathrm{Fe}, \mathrm{Co}$ and $\mathrm{Ni}$ is calculated. We considered the contribution to conductivity from the $s$-electrons, described within the model of nearly free electrons. The role of the partially occupied $d$-bands is reduced to resonance scattering of the $s$-electrons on $d$-states. The interaction of the $s$ - and $d$-electrons is described by the hybridization potential of $s$ - and $d$-states. The interaction with the ions, not including the partially occupied $d$-states, is described using the pseudopotential of the electronion interaction. The electroresistivity of the alloys is calculated in the second order of the perturbation theory in pseudopotential and hybridization potential. The concentration dependance of electroresistivity of the binary alloys approaches the linear regime as the resonance scattering of the $s$-electrons on $d$-states prevails over the scattering on the ions. The calculations exhibit good agreement with the experimental data.
\end{abstract}

Key words: electroresistivity of alloys, liquid transition metals

PACS: 72.14.E, 72.15.C

\section{Introduction}

The nowadays theory of the electron transport phenomena began from the seminal work of Ziman [1]. In his study the electroconductivity of simple metals was calculated using the model of nearly free electrons in the second order of the perturbation theory in pseudopotential of the electron-ion interaction. In the following paper [2] this approach was extended to deal with the binary alloys of the simple liquid metals. The results of that paper provide excellent agreement of the concentration dependence of the simple liquid metals [3-5] with the experiment and is extensively used to the present day [7-10].

In later works [10], the Ziman's formula [1] was generalized to the case of transition liquid metals by introducing the single-particle t-matrix to replace the pseudopotential of the electron-ion interaction. The idea behind this approach is that the pseudopotential of the electron-ion interaction in the transition metals is not a 
sufficiently small parameter, but the t-matrix, in fact, constitutes the sum of the infinite perturbation series in pseudopotential. The attempts to use this method in order to calculate the resistivity of the binary alloys of transition metals did not bring much of a success [11]. Just like in the case of simple liquid metals, the concentration dependence appeared to be essentially nonlinear, with the tendency to conform to the Nordheim rule. At the same time the experimental results suggest that electroconductivity of liquid binary alloys of transition metals does not show strong concentration dependence [12-14]. In many cases this dependence is close to the linear one $[13,14,11]$.

Another description of the electron transport phenomena is based on the Mott model [15]. It describes the scattering of the conductivity $s$-electrons on the ionic subsystem using the potential of the hybridization of $s$ - and $d$-states. This approach was successfully employed in calculating the conductivity of the liquid transition metals [16] (for more details see [17]). However, the concentration dependence of the resistivity of binary alloys of transition metals calculated using this method significantly differs from the experimental values, and appears to be almost linear in this case.

In this paper we are using two-parameter model to describe the electron transport phenomena in disordered alloys of transition metals. The interaction of the conduction electrons, which are only s-electrons, with the ion subsystem includes two different mechanisms. The interaction with the ionic core, not including the $d$-states of the partially occupied $d$-shells, is treated with the use of the pseudopotential of the electron-ion interaction. The interaction with the $d$-electrons is incorporated within the $s$ - $d$ hybridization framework. The first mechanism leads to the concentration dependency that is similar to that of simple metals, while the second one results in a linear concentration dependency. The interplay of these two contributions shapes the concentration dependency of electroconductivity of any specific alloy.

\section{Hamiltonian}

We chose the model Hamiltonian of the electron subsystem of the binary alloy of transition metal in the form

$$
H=H_{s}+H_{A W}+H_{B W}+H_{A \Delta}+H_{B \Delta}+H_{A d}+H_{B d} .
$$

Here

$$
H_{s}=\sum_{k} \varepsilon_{k} a_{k}^{+} a_{k}
$$

is the Hamiltonian of the noninteracting gas of $s$-electrons, $a_{k}^{+}, a_{k}$ are the operators of nucleation and annihilation of the electron in the state with the wave vector $\mathbf{k}$, respectively,

$$
\varepsilon_{k}=\hbar^{2} k^{2} / 2 m
$$


is the energy of the free electron;

$$
\begin{aligned}
H_{A W} & =V^{-1} \sum_{\mathbf{k}, \mathbf{q}} w_{A}(q) \rho_{A}(\mathbf{q}) a_{k}^{+} a_{k}, \\
H_{B W} & =V^{-1} \sum_{\mathbf{k}, \mathbf{q}} w_{B}(q) \rho_{B}(\mathbf{q}) a_{k}^{+} a_{k}
\end{aligned}
$$

are the Hamiltonians of the interaction of $s$-electrons with the ionic cores of types $A$ and $B, w_{A}(q), w_{B}(q)$ are the formfactors of the corresponding model local pseudopotentials, and $V$ is the volume of the system,

$$
\begin{aligned}
& \rho_{A}(\mathbf{q}, t)=\sum_{n=1}^{N_{A}} \exp \left(-\mathbf{i q} \mathbf{R}_{A n}\right), \\
& \rho_{B}(\mathbf{q}, t)=\sum_{n=1}^{N_{B}} \exp \left(-\mathbf{i q} \mathbf{R}_{B n}\right)
\end{aligned}
$$

are the Fourier transforms of the densities of the electron subsystems of the $A$ and $B$ types, $N_{A}, N_{B}$ - the quantities of the ions of each type, $\mathbf{R}_{A n}, \mathbf{R}_{B n}$ are the radiusvectors of the corresponding ions;

$$
\begin{aligned}
& H_{A \Delta}=V^{-1 / 2} \sum_{\mathbf{k}, n=1}^{N_{A}}\left[\Delta_{A, \mathbf{k}, n, m} a_{\mathbf{k}}^{+} b_{A, n, m}+\Delta_{A, n, m, \mathbf{k}} b_{A, n, m}^{+} a_{\mathbf{k}}\right], \\
& H_{B \Delta}=V^{-1 / 2} \sum_{\mathbf{k}, n=1}^{N_{B}}\left[\Delta_{B, \mathbf{k}, n, m} a_{\mathbf{k}}^{+} b_{B, n, m}+\Delta_{B, n, m, \mathbf{k}} b_{B, n, m}^{+} a_{\mathbf{k}}\right]
\end{aligned}
$$

are the Hamiltonians of the interaction between $s$ - and $d$-electrons, $b_{A, n, m}^{+}, b_{A, n, m}$, $b_{B, n, m}^{+}, b_{B, n, m}$ are the operators of nucleation and annihilation of $d$-electrons in the state characterized by the set of quantum numbers $m$ on the $n$-th ion of the corresponding type, $\Delta_{A, \mathbf{k}, n, m}, \Delta_{A, n, m, \mathbf{k}}, \Delta_{B, \mathbf{k}, n, m}, \Delta_{B, n, m, \mathbf{k}}$ are the matrix elements of the hybridization potentials of $s$-electrons with the $d$-electrons of corresponding types. Just like in the case of matrix elements of pseudopotential we assume that they can be factorized, namely

$$
\begin{aligned}
& \Delta_{A, \mathbf{k}, n, m}=\Delta_{A m}(k) \exp \left(-\mathrm{i} \mathbf{k} \mathbf{R}_{A n}\right) \\
& \Delta_{A, n, m, \mathbf{k}}=\Delta_{A m}(k) \exp \left(\mathbf{i} \mathbf{k} \mathbf{R}_{A n}\right) \\
& \Delta_{B, \mathbf{k}, n, m}=\Delta_{B m}(k) \exp \left(-\mathrm{i} \mathbf{k} \mathbf{R}_{B n}\right) \\
& \Delta_{B, n, m, \mathbf{k}}=\Delta_{B m}(k) \exp \left(\mathbf{i} \mathbf{k} \mathbf{R}_{B n}\right)
\end{aligned}
$$

Finally,

$$
\begin{aligned}
H_{A d} & =\sum_{n=1, m}^{N_{A}} \varepsilon_{A, n, m} b_{A, n, m}^{+} b_{A, n, m}, \\
H_{B d} & =\sum_{n=1, m}^{N_{B}} \varepsilon_{B, n, m} b_{B, n, m}^{+} b_{B, n, m}
\end{aligned}
$$


are the Hamiltonians of noninteracting $d$-electrons of corresponding types, $\varepsilon_{A, n, m}$, $\varepsilon_{B, n, m}$ are the energies of the $d$-states in corresponding pure metals.

The model Hamiltonian put forward in this paper corresponds to the following representation of the wave functions in secondary quantization formalism:

$$
\begin{aligned}
\psi(\mathbf{r}) & =\sum_{\mathbf{k}} a_{\mathbf{k}}|\mathbf{k}\rangle+\sum_{n=1, m}^{N_{A}} b_{A, n, m}|A, n, m\rangle+\sum_{n=1, m}^{N_{B}} b_{B, n, m}|B, n, m\rangle, \\
\psi^{+}(\mathbf{r}) & =\sum_{\mathbf{k}} a_{\mathbf{k}}^{+}\langle\mathbf{k}|+\sum_{n=1, m}^{N_{A}} b_{A, n, m}^{+}\langle A, n, m|+\sum_{n=1, m}^{N_{B}} b_{B, n, m}^{+}\langle B, n, m|,
\end{aligned}
$$

where $|\mathbf{k}\rangle,\langle\mathbf{k}|$ are the orthogonolized plane waves [18], describing the state of the $s$-electrons. They are obtained by orthogonalizing the plane waves to the wave functions of $d$-electrons of the partially occupied $d$-bands. At that, the mutual orthogonality holds. $|A, n, m\rangle,|B, n, m\rangle,\langle A, n, m|,\langle B, n, m|$ are the wave functions of $d$-electrons that form the partially occupied $d$-bands. They are orthogonolized similarly to the wave functions of all the other ions in the metal. The orthogonolized plane waves and the orthogonolized atomic wave functions constitute the complete orthogonal set of functions.

As a model Hamiltonian of the electron subsystem in the coordinate representation we chose the following

$$
H=\sum_{l} H_{l}
$$

where

$$
H_{l}=T_{l}+\sum_{m=1}^{N_{A}} V_{A}\left(\left|\mathbf{r}_{l}-\mathbf{R}_{A m}\right|\right)+\sum_{m=1}^{N_{B}} V_{B}\left(\left|\mathbf{r}_{l}-\mathbf{R}_{B m}\right|\right) .
$$

Here $T_{l}$ is the kinetic energy operator of the $n$-th $s$-electron, $V_{A}\left(\left|\mathbf{r}_{l}-\mathbf{R}_{A m}\right|\right), V_{B}\left(\mid \mathbf{r}_{l}-\right.$ $\mathbf{R}_{B m} \mid$ ) are the self-consistent potential energies of the interaction between $s$-electrons and the ions of different types. On transition to the representation of secondary quantization in the above discussed mixed basis, the following matrix elements appear

$$
\begin{aligned}
&\left\langle\mathbf{k}\left|H_{l}\right| \mathbf{k}^{\prime}\right\rangle=\varepsilon_{k} \delta_{\mathbf{k k}^{\prime}}+w_{A}\left(\left|\mathbf{k}-\mathbf{k}^{\prime}\right|\right) \rho_{A}\left(\mathbf{k}-\mathbf{k}^{\prime}\right)+w_{B}\left(\left|\mathbf{k}-\mathbf{k}^{\prime}\right|\right) \rho_{B}\left(\mathbf{k}-\mathbf{k}^{\prime}\right), \\
&\left\langle\mathbf{k}\left|H_{l}\right| A, n, m\right\rangle=\Delta_{A, \mathbf{k}, n, m}, \quad\left\langle A, n, m\left|H_{l}\right| \mathbf{k}\right\rangle=\Delta_{A, n, m, \mathbf{k}}, \\
&\left\langle\mathbf{k}\left|H_{l}\right| B, n, m\right\rangle=\Delta_{B, \mathbf{k}, n, m}, \quad\left\langle B, n, m\left|H_{l}\right| \mathbf{k}\right\rangle=\Delta_{B, n, m, \mathbf{k}}, \\
&\left\langle A, n, m\left|H_{l}\right| A, n, m\right\rangle=\varepsilon_{A, n, m}, \quad\left\langle B, n, m\left|H_{l}\right| B, n, m\right\rangle=\varepsilon_{B, n, m} .
\end{aligned}
$$

The matrix elements of the type $\left\langle A, n, m\left|H_{l}\right| B, n^{\prime}, m^{\prime}\right\rangle$ can be neglected in the cases where the nearly free model is applicable.

\section{Resistance coefficient}

To calculate the specific electroresistivity coefficient of the liquid binary alloys we use the approach similar to that used at the calculation of resistivity of the pure 
transition metals $[17,19]$. At that

$$
\rho=\frac{n}{e^{2} m} \frac{1}{\tau}
$$

where

$$
n=k_{\mathrm{F}}^{3} / 3 \pi^{2}
$$

is the density of conduction electrons,

$$
k_{\mathrm{F}}=\left(3 \pi^{2} z / v\right)^{1 / 3}
$$

is the Fermi wave vector of the conduction electrons,

$$
z=c_{A} z_{A}+c_{B} z_{B}
$$

is the average valency of the alloy, $z_{A}, z_{B}$ are the valencies of the alloy components (number of $s$-electrons per ion), $c_{A}=N_{A} /\left(N_{A}+N_{B}\right), c_{B}=N_{B} /\left(N_{A}+N_{B}\right)$ are the concentrations of the alloy components, such that $c_{A}+c_{B}=1$,

$$
v=c_{A} v_{A}+c_{B} v_{B}
$$

is the average volume per ion in the alloy, $v_{1}, v_{2}$ are the volumes per ion in the pure metals.

In the second order of the perturbation theory in pseudopotential and the hybridization potential, the inverse relaxation time is as follows:

$$
\tau^{-1}=\tau_{\mathrm{Z}}^{-1}+\tau_{\mathrm{M}}^{-1}
$$

Here, the first contribution stems from the scattering of the electrons on the ions. For the pure metals it is the Ziman's relaxation time [1]

$$
\tau_{\mathrm{Z}}^{-1}=\frac{m}{4 \pi v \hbar^{3} k_{\mathrm{F}}^{3}} \int_{0}^{2 k_{\mathrm{F}}}\left[\frac{w(q)}{\varepsilon(q)}\right]^{2} S(q) q^{3} \mathrm{~d} q .
$$

Here $\varepsilon(q)$ is the dielectric permittivity of the conduction electrons, $S(q)$ is the static structure factor of the ion subsystem. The distinctive property of this formula is its strong dependence on the structure of the metal due to the presence of a structure factor.

This contribution for the binary alloys can be calculated using the following substitution [2]

$$
\begin{aligned}
w(q) S(q, \omega) \rightarrow & c_{A} c_{B}\left[w_{A}(q)-w_{B}(q)\right]^{2} \\
& +c_{A}^{2} w_{A}^{2}(q) S_{A A}(q)+2 c_{A} c_{B} w_{A}(q) w_{B}(q) S_{A B}(q)+c_{B}^{2} w_{B}^{2}(q) S_{B B}(q),
\end{aligned}
$$

where $S_{A A}(q), S_{A B}(q), S_{B B}(q)$ are the partial structure factors of the ion subsystem of a binary alloy. The same result can be obtained by rigorous treatment. From 
this expression one can conclude that the concentration dependence of the binary alloys is nonlinear and can have a substantially parabolic character if the formfactors $w_{A}(q), w_{B}(q)$ significantly differ for distinct components. In this case the first contribution can take especially large values.

The second contribution in (26) corresponds to the Mott's relaxation time [15]

$$
\tau_{\mathrm{M}}^{-1}=\frac{2 \pi}{\hbar v}\left|\Delta\left(k_{\mathrm{F}}\right)\right|^{2} G\left(\varepsilon_{\mathrm{F}}\right)
$$

Here $G\left(\varepsilon_{\mathrm{F}}\right)$ is the density of the $d$-states, normalized to the number of $d$-states per ion. There are 10 such states in $3 d$-metals.

This contribution to the inverse relaxation time for the binary alloys of transition metals can be obtained using the following substitution

$$
\left|\Delta\left(k_{\mathrm{F}}\right)\right|^{2} G\left(\varepsilon_{\mathrm{F}}\right) \rightarrow c_{A} \Delta_{A}^{2}\left(k_{\mathrm{F}}\right) G_{A}\left(\varepsilon_{\mathrm{F}}\right)+c_{B} \Delta_{B}^{2}\left(k_{\mathrm{F}}\right) G_{B}\left(\varepsilon_{\mathrm{F}}\right) .
$$

The concentration dependance of this contribution is linear. If it were the only contribution to the inverse relaxation time of the binary alloy it would have been linear as well. So, in the second order of perturbation theory, the inverse relaxation time is the superposition of two contributions previously suggested in order to separately deal with simple and transition metals. In the higher orders of perturbation theory the superposition principle fails [19].

\section{Results and discussion}

The huge number of parameters characterizing the components of alloy makes the numerical analysis of the concentration dependence of electroresistivity quite a complicated task. At that, the use of model expressions for various matrix elements, partial structure factors and the density of $d$-states is inevitable.

For the partial structure factors of the liquid binary alloy of transition metals we use the exact solution of the Percus-Yevick of the hard-sphere model [20], the packing fractions are taken from [21]. If the packing fraction and the number densities in the ion subsystem are known we can easily calculate the corresponding hard sphere diameters.

For the formfactor of the pseudopotential we use the model local pseudopotential due to Krasko-Gurskiy [22]. It includes two fitting parameters: the effective ion diameter and effective depth of the potential well induced by the ion for the conduction electrons. To reduce the number of fitting parameters we put the effective ions dimensions equal to those of hard spheres. The second fitting parameter can be determined from the contribution to the resistivity caused by the scattering on the ion cores. We operate on the assumption that for pure metals with completely or partially occupied $d$-bands this is the only relevant contribution. As long as Fe, Co, $\mathrm{Ni}$ are the $3 d$ metals, and in the fourth period of the periodic table that contains these metals, the metal row is preceded by $\mathrm{Ca}$ with no $d$-electrons at all, and ends with the $\mathrm{Cu}$, the contribution of interest should accept values between the resistivities of $\mathrm{Ca}$ and $\mathrm{Cu}$. In view of the absence of more precise information, we use the 
following linear interpolation

$$
\tau_{n}^{-1}=\tau_{\mathrm{Ca}}^{-1}+n\left(\tau_{C u}^{-1}-\tau_{\mathrm{Ca}}^{-1}\right) / 10
$$

where $n$ is the number of $d$-electrons in the metal, the completely filled shell contains 10 electrons. In accordance with this formula, the contribution $\tau_{\mathrm{Z}}^{-1}$ for the metals considered in the paper should constitute $20 \%-25 \%$ from $\tau_{\mathrm{M}}^{-1}$. Consequently, the concentration dependence of the resistivity can be significantly nonlinear. Using the experimental data for resistivity of $\mathrm{Ca}$ and $\mathrm{Cu}$, we can specify the contribution under discussion for Fe, Co, Ni. Then, yet undetermined parameter of the pseudopotential can be found from the condition that this contribution is described by formula (27).

For the dielectric permittivity of the conduction electrons we use the random phase approach allowing for the exchange interaction and correlations of conduction electrons in local field approximation [23].

For the density of states we use the following expression

$$
G(\varepsilon)=\frac{10}{\Gamma \sqrt{2 \pi}} \exp \left[-\frac{\left(\varepsilon-\varepsilon_{d}\right)^{2}}{2 \Gamma^{2}}\right]
$$

Here $\varepsilon_{d}$ is the mean energy of the $d$-states, $\Gamma$ is the half-width of this zone. The values of these parameter for $\mathrm{Fe}, \mathrm{Co}, \mathrm{Ni}$ were taken from [24].

We adopt the hybridization potential in the spherical symmetric form, proposed at $[25]$

$$
\Delta(k)=A k^{2},
$$

where $A$ is the fitting parameter. The values of $A$ are chosen such that the formula (21) with the relaxation time (26) produce the resistivity values of pure liquid transition metals. It should be noted that at calculation of the concentration dependence of the resistivity of the binary alloys it is conventional to fit the experimental data at the limiting points of the corresponding curve, that describe the resistivity of pure metals. The curvature of the theoretical curves for the concentration dependence of resistivity is determined by the relation between $\tau_{\mathrm{Z}}^{-1}$ and $\tau_{\mathrm{M}}^{-1}$ contributions. The following figures illustrate the concentration dependence of resistivity of the FeNi, FeCo, CoNi alloys. All the parameters of the pure metals required for calculations are taken at a temperatures of their melting. The experimental values of the electroresistivity coefficients are taken from [14].

The graphs bring about a good agreement between the theory and experimental data.

Though the current paper deals with the liquid state of these metals, the obtained results hold for amorphous metals as well. It follows from the fact that the concentration dependencies of the electroresistivity in liquid and amorphous states are virtually the same. The curves can be brought into coincidence by the translation. [14]. The latter remark is particularly important, because of the recent growth of interest to the electron transport phenomena in amorphous metals and their alloys $[26,27]$. 


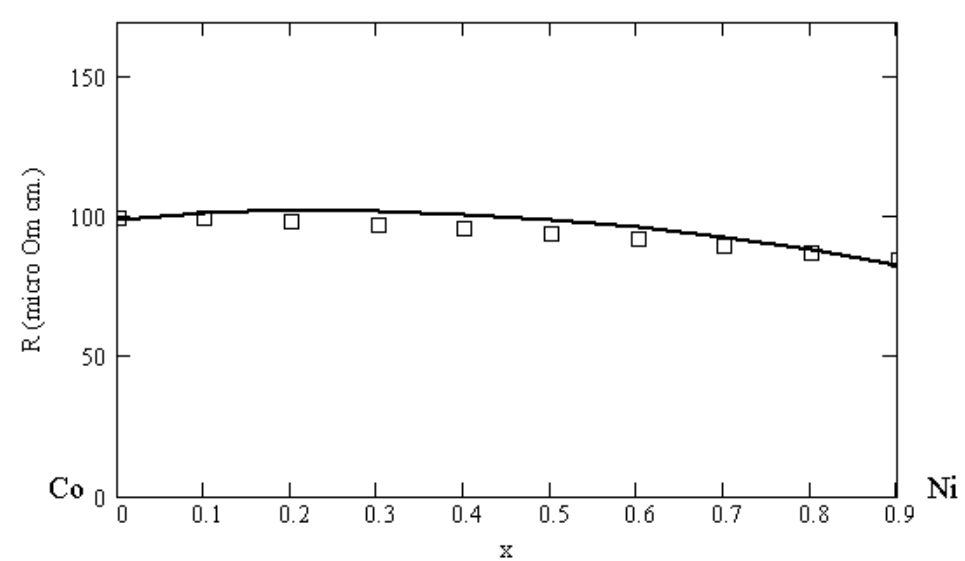

Figure 1. Concentration dependence of electroresistivity for the CoNi alloy, - theoretical curve, $\square$ - experimental data.

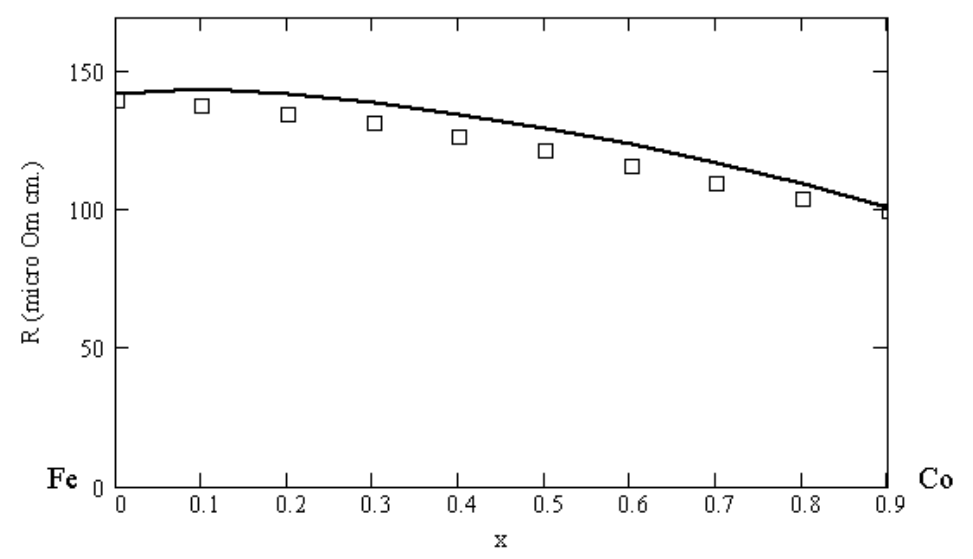

Figure 2. Concentration dependence of electroresistivity for the FeCo alloy, - theoretical curve, $\square$ - experimental data.

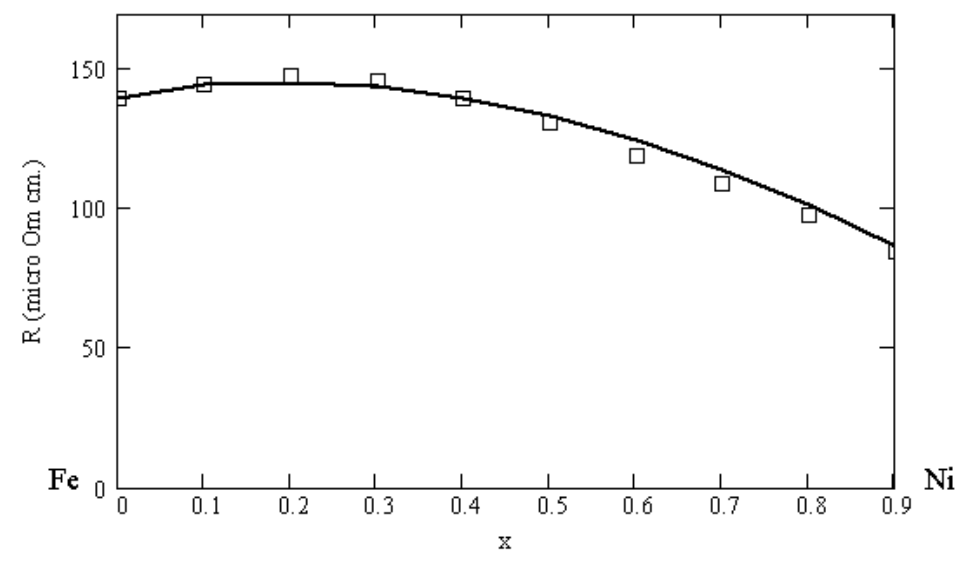

Figure 3. Concentration dependence of electroresistivity for the FeNi alloy, - theoretical curve, $\square$ - experimental data. 


\section{References}

1. Ziman J.M. A theory of electrical properties of liquid metals. I. The monovalent metals. // Phil. Mag., 1961, vol. 6, No. 68, p. 1013-1034.

2. Faber T.E., Ziman Y.M. A theory of the electrical properties of liquid metals. III. The resistivity of binary alloys. // Phil.Mag., 1965, vol. 11, No. 109, p.153-173.

3. Bush G., Giinterodt H.-J. Electronic properties of liquid metals and alloys. // Solid. St. Phys., 1974, vol. 29, p. 235-313.

4. Hoshino K. Structure of multi-component hard-sphere mixtures-application to the liquid Li-Pb alloy. // J. Phys. F: Met. Phys., 1983, vol. 13, p. 1981-1992.

5. Gopala Rao R.V., Venkatesh R. Evaluation of electrical resistivities of Hg-In alloys. // Phys. Lett. A, 1989, vol. 141, No. 1,2, p. 78-80.

6. Meijer J.A., Van der Lugt W. Resistivity of liquid K-Bi and Cs-Bi alloys. // J. Phys.: Condens. Matter, 1989, vol. 1, p. 9779-9784.

7. Wang Q., Chen X., Lu K. Electrical resistivity and absolute thermopower of liquid GaSb and InSb alloys. // J. Phys.: Condens. Matter, 2000, vol. 12, No. 24, p. 52015207.

8. Ben Moussa A., Giordianengo B., Humbert J.C., Chaaba H., Bestandji M., Gasser K.G. Electrccal prpoerties of liquid Cd-Te alloys. // Phys. Rev. B, 2000, vol. 62, No. 24, p. 16632-16637.

9. Wang Q., Chen X., Lu K. Concentration and temperature dependence of the electrical resistivity of liquid gallium-antimony alloys. // J. Phys.: Condens. Matter, 2001, vol. 13, No. 37 , p. 8445-8453.

10. Sharan P.K., Mishra A.K. Electrical and thermodynamic properties of liquid alloys // Indian J. Phys. A. 2000, vol. 74, No. 4, p. 395-397.

11. Hirata K., Waseda Y., Jains A., Srivastava R. Resistivity of liquid transition metals and their alloys using the t-matrix. // J. Phys. F.: Met. Phys., 1977, vol. 7, No. 3, p. 419-425.

12. Pavuna D. On the magnitude of the electrical resisitivity of liquid and glassy transition metal alloys. // J. Non-Cryst. Solids, 1984, vol. 61-62, p. 1359-1358.

13. Kita Y., Morita Z. The electrical resistivity of liquid Fe-Ni, Fe-Co and Ni-Co alloys. // J. Non-Cryst. Solids, 1984, vol. 61-62, p. 1079-1084.

14. Ocko M., Babic E. Comparison between the resistivities of amorphous and liquid FeCo, FeNi and CoNi alloys. // Zeitschrift fur Physikalische Chemie Neue Folge, 1988, vol. 157 , p. $663-667$.

15. Mott N.F. The electrical resistivity of liquid transition metals. // Phil. Mag., 1972, vol. 26, No. 1, p. 1249-1261.

16. Fujiwara T. Electrical states and transport in amorphous and liquid transition metals Fe, Co and Ni. // J. Phys. F.: Met. Phys., 1979, vol. 9, No. 10, p. 2011-2024.

17. Shvets V.T. Green functions in the theory of metals. Odessa, Latstar, 2002, p. 400. (in Ukrainian)

18. Yukhnovkii I.R., Gurskiy Z.O. Quantum Statisitical Theory of disordered systems. Kiev, Naukova Dumka, 1991, p. 288. (in Russian)

19. Shvets V.T., S.Savenko, S.Datsko. Perturbation theory for electrical resistivity of liquid transition metals. // Condens. Matter Phys., 2002, vol. 5, No. 3(31), p. 511-522.

20. Lebowitz J.L. Exact solution of generalized Percus-Yevick equation for a mixture of hard-sphere. // Phys. Rev., 1964, vol. 133, No. 4A, p. A895-A899. 
21. Waseda J. The structure of non-crystalline materials and amorphous solids. Mm.Crow-Hill International Book Company, 1985, p. 324.

22. Krasko G.L., Gurskii Z.A. On the one model pseudopotential.

// Pis'ma Zh. Eksp. Tero. Fiz., vol. 9, No. 10, p. 596-601.

23. Geldart D.J.M., Vosko S.H. The screening function of an interacting electron gas.

// Can. J. Phys., 1966, vol. 44, No. 9, p. 2137-2171.

24. Dagens L. The resonant model potential method: a narrow d-band approximation to d-metal bandstructure, model Green function and density response function.

// J. Phys. F: Met. Phys., 1981, vol. 11, p. 2327-2344.

25. Harrison W.A. Electronic structure and the properties of solids. The Physics of the chemical bond. San Francisco, W.H. Freeman and Company, 1980, p. 334.

26. Nemolashenko V.B., Romanova A.V., Ilyinskiy A.I., Maslov V.V. et al., Amorphous Metallic Alloys. Kiev, Naukova Dumka, 1987, p. 248. (in Russian)

27. Shpack A.P., Kunitskiy Y.A., Lysov V.I. Claster and Nanostructure Materials. Kiev, Akademperiodika, 2002, p. 540.(in Russian)

28. Evans R., Greenwood P.A., Lloyd P. Calculations of the transport properties of liquid transition metals. // Phys. Lett. A, 1971, vol. 35, No. 2, p. 57-58.

\title{
Електропровідність сплавів перехідних рідких металів
}

\author{
В.Т.Швець, С.В.Савенко, С.В.Дацько \\ Одеська державна академія холоду, \\ Дворянська вул., 1/3, 65026, Одеса, Україна
}

Отримано 22 квітня 2004 р.

Розрахована концентраційна залежність електроопору бінарних сплавів рідких перехідних металів $\mathrm{Fe}, \mathrm{Co}, \mathrm{Ni}$. Електронами провідності вважаються лише $s$-електрони, що описуються в моделі майже вільних електронів. Роль $d$-електронів частково заповненої $d$ оболонки зводиться до резонансного розсіяння $s$-електронів на $d$ станах. Взаємодія $s$-електронів з іонною підсистемою, що не містить частково заповнених $d$-станів, описується псевдопотенціалом електрон-іонної взаємодії. Взаємодія $s$ - та $d$ - електронів описується потенціалом гібридизації $s$ - і $d$-станів. Електроопір сплавів розраховується у другому порядку теорії збурень за псевдопотенціалом та потенціалом гібридизації. Концентраційна залежність електроопору бінарних сплавів рідких перехідних металів тим ближча до лінійної, чим більше резонансне розсіяння $s$-електронів на $d$-станах перевищує їх розсіяння на іонній підсистемі. Результати чисельних розрахунків знаходяться у добрій відповідності з експериментальними даними.

Ключові слова: електроопір сплавів, рідкі перехідні метали

PACS: 72.14.E, 72.15.C 